\title{
Havacılık Sektöründe Psikolojik Sahiplenme ve Devamsızlık İlişkisi
}

\author{
Leyla ŞENOL*, Burcu ÜZÜM**
}

\begin{abstract}
Öz
İșe devamsızlık örgütler için iș kaybı olușturacağından maliyetlerin artmasına neden olacaktır. Bu bağlamda çalışanların ișe devamlarının sağlanabilmesi için psikolojik sahiplenmenin olușturulması yönünde politikalar geliștirilmesi önemlidir. Bu araștırma ile havacılık sektöründe çalışanların psikolojik sahiplenme algılarının ișe devamsızlığı etkileyip etkilemediğinin ölçülmesi amaçlanmıștır. Bu ilișkinin belirlenmesi amacıyla nicel bir araştırma yapılması hedeflenmiştir. Bu çalışma Sabiha Gökçen ve Cengiz Topel hava alanlarında faaliyet gösteren işletme çalışanları üzerinde uygulanmıştır. Araștırma verilerinin analizine göre psikolojik sahiplenme ile işe devamsızlık arasında doğrudan bir ilişki olmadığı görülmüştür. Ancak devamsızlığın alt boyutları ile psikolojik sahiplenme arasında anlamlı bir ilișki bulunmuştur. Bu sonuç çalışanların ișe devamsızlık oranını düşürmesi yönünde örgüt yönetimini memnun edecek bir sonuçtur.

Anahtar Kelimeler: Psikolojik Sahiplenme, Devamsızlık, Havacılık, Havacılık Sektörü, Psikoloji
\end{abstract}

\section{Psychological Ownership and Absenteeism Relationship in the Aviation Sector}

\section{Abstract}

Due to the fact that absenteeism causes job loss, it may lead to an increase in the cost. In that sense, it is important to establish a policy for forming psychological appropriation in order to make employees come to work. In this study, it is aimed to measure if the employees' sense of psychological appropriation in aviation industry affects their absenteeism. It is intended to make a quantitative research so as to identify this relationship. This study has been applied to the employees working at the managements in Sabiha Gökçen and Cengiz Topel airports. According to the anaylsis of the research data, it has been understood that there is not a direct relationship between psychological appropriation and absenteeism. Nevertheless, it has been concluded that there is a meaningful relationship between sub-dimnesions of absenteeism and psychological appropriation. This result is a result that will satisfy the organization management in reducing the rate of absenteeism of employees.

Keywords: Psychological Appropriaiton, Absenteeism, Aviation Industrys, Aviation, Psychology

\footnotetext{
Özgün Araştırma Makalesi (Original Research Article)

Geliş/Received: 17.05 .2019

Kabul/Accepted: 18.08 .2020

DOI: https://dx.doi.org/10.17336/igusbd.566559

* Dr., Kocaeli Üniversitesi, Ali Rıza Veziroğlu MYO, Emlak ve Emlak Yönetimi Bölümü, Kocaeli,

Türkiye, E-posta: senolleyla4@gmail.com ORCID https://orcid.org/0000-0002-5780-9690

** Dr., Kocaeli Üniversitesi, Kocaeli Meslek Yüksekokulu, Uzaktan Eğitim, Kocaeli, Türkiye,

E-posta: burcugokay@gmail.com ORCID https://orcid.org/0000-0001-8675-8952
} 


\section{Giriş}

Havacılık sektörü; genel havayolu işletmeleri, zirai ilaçlama, balon, kargo uçakları, bakım ișletmeleri gibi geniş bir yelpazede yer almaktadır. Havacılık sektörü ülkeler arası sınırları ortadan kaldırarak kültürel bağlar kurmakta ekonomik açıdan da ülkelerin refah düzeyini artırmaktadır. Havacılık sektörünün ekonomiye katkısı ihtiyaçlar hiyerarşisinin ilk basamağı olan gıda harcamaları ile karşılaştırıldığında dünya gayri safi hasılasındaki yeri iki kat fazladır.

Sektörel büyüme bakımından Türkiye'nin göz bebeği olan havacıllk sektörü küresel işletmelerle rekabet etmektedir. Türkiye havayolu sektörü içerisinde taşıdığı yolcu sayısı ile dünyada 10. sırada yer alırken Avrupa'da 4. sıradadır. Bu sıralama ile Türkiye'nin dünya havacılık sektöründe kendine geniş bir yer edindiği görülmektedir (www.uab.gov.tr, 2018). 2019 yılı içinde havacılık sektörünün cirosu 110 milyar dolara ulaşmış durumdadır. Havacılık sektöründe çalıșan personel sayısı ise 200 bin civarındadır (www.apronmedya.com; www.ekonomihaber.com).

Hızla büyümeye devam eden havacılık sektöründe Türkiye'de hizmet veren yaklașık 160 havayolu ișletmesi bulunmaktadır. Mevcut ișletmeler sivil havayolu, hava taksi genel havacılık ve balon işletmesi olduğu düşüldügünde gayri safi hasıladaki paydan her bir işletme daha büyük pay almak arzusundadır. Bu arzu birbirine benzer teknolojiyi kullanan işletmelerin sahip olduğu insan kaynağını en verimli şekilde kullanılmasıyla gerçekleşebilir. Bu bağlamda insan kaynakları örgütlerin önemli üretim etmenlerinden biridir ve işletmelerin hedeflerine ulaşmasında önemli bir rol oynamaktadır. Verimliliğin arttırılması için oluşturulacak olan politikalarla iş gücü daha etkin kullanılabilir.

Havacılık sektörü çalıșanlarının psikolojik sahiplenme algıları ile ișe devamsızlık arasında anlamlı bir ilişski olup olmadığının belirlenmesi araştırmanın amacını oluşturmaktadır. Bu ilişkinin insan kaynakları yönetimi açısından önemli olduğu düşünülmektedir. Literatür taraması sonucunda araştırmaya konu olan iki kavramın beraberce havacılık sektöründe pek fazla araștırılmadığı belirlenmiştir. Araştırmanın alan yazınına, havayolu işletmeleri yönetimlerine ve ilgili kavramlara yönelik araștırma yapanlara katkı sağlayacağı umulmaktadır.

\section{LITERATÜR ARAŞTIRMASI}

\subsection{Psikolojik Sahiplenme}

İnsanlar bir takım amaçlardan dolayı sahiplenme duygusu yaşayabilmektedirler. $\mathrm{Bu}$ amaçlar doğrultusunda belirli durumlarda, çalışanlarda örgüte ve örgütsel unsurlara yönelik sahiplenme duygusu gelișebilmektedir. Psikolojik sahiplenme; kişilerin kendinin olmadığı halde kendini bazı nesnelerin sahibiymiş gibi hissetmesidir. Çalışanların tutum ve davranışlarını etkileyen psikolojik sahiplenme; çalışanın örgütün kendine ait olduğunu hissetmesi olarak açlklanabildiği gibi (Pierce vd., 2003, akt., Yeşil vd., 2015, s. 65), iş yerine, çalışma arkadaşlarına, düşünceye, tavsiyeye, ișe veya donanıma karşı hissedilen sahiplenme olarak da ifade edilmektedir (Van Dyne \& Pierce, 2004, s. 439).

Psikolojik sahiplenme, iş ortamında taahhüt, tanımlama ve içselleştirme şeklinde ortaya çıkabilir (Pierce vd., 2001, s. 298). Yapılan araştırmalar, sahiplenme kavramını benliğin bir uzantısı gibi görmekte ve çoğunlukla benliğe sahip olunan değerlerin bir bütünü olarak açıklamaktadır (Litwinski, 1947, s. 240; Russell, 1988, s. 139; Yeşil vd., 2015, s. 61). Psikolojik sahiplenme kavramı; tutum ve davranışla, benlik ve sorumluluk duygusu ile ilişki içindedir. Kişiler, somut ve soyut kavramlara ilişkin sahiplik hissettiğinde daha pozitif bir tutum oluşmaktadır. Hatta benliğin devamı olarak görülüp sahiplenen varlığa karşı bir sorumluluk duygusu gelişmesi mümkündür. Sahiplenmenin tutum ve davranışlara etkisi mevcut koşullardaki yapılardan (iş doyumu ve örgüte bağlılık 
gibi) farklı bir durumu ifade etmektedir (Van Dyne \& Pierce, 2004, s. 459). Psikolojik sahiplenme resmi mülkiyetin olmadığı durumlarda oluşan sahiplenme duygusu olarak da açıklanabilir (Van Dyne \& Pierce, 2004, s. 459; Mayhew vd., 2007, s. 477).

Psikolojik yönden olumlu duygu beslemek (Van Dyne \& Pierce, 2004, s. 439) benlikle ilgilidir. Sahiplenme, bir nesneyi psikolojik açıdan "benimki" şeklinde kabul etmektir. Kısaca psikolojik sahiplenmedeki hedef olan somut ya da soyut nesne kimliğin bir tamamlayıcısı ve kimliği tanımlayan bir sembole dönüşmektedir (Pierce vd., 2001, s. 299; Avey vd., 2009, s. 174). Kişilerin çevrelerini değiștirme arzuları, bireyin sahiplenme arzusunun gelişmesine neden olmaktadır (Pierce vd., 2001, s. 300). Bölgecilik ise sahiplenmenin tutumsal açıdan yönünü çizmektedir (Brown vd., 2005, s. 577). Sahiplenme, sorumluluk duygusuyla da ilgilidir. Kişinin inançlarını, beklentilerini başka kișilerin onaylaması ihtiyacıyla ilgili bir duygudur (Lerner \& Tetlock 1999, s. 255, Avey vd., 2009, s. 173).

Örgütsel davranış yazınında psikolojik sahiplenme ile ilgili araștırmaların, sosyoloji ve psikoloji alanlarında yapıldığı görülmektedir (Pierce \& Jussila, 2010, s. 834). Bu bağlamda örgütsel davranıșı açıklayan çalışmalar şeklinde sürdürüldüğü belirtilebilir (Uçar, 2017, s. 167). Psikolojik sahiplenmeye dayanak olan güdüler üzerinde de araștırmalar olduğu görülmektedir (Mayhew vd., 2007, s. 500; Van Dyne \& Pierce, 2004, s. 459; Pierce vd., 2001, s. 459; Pierce \& Rodgers, 2004, s. 613).

Psikolojik sahiplenmeyle örgütsel bağlılık, işi tatmini (Van Dyne \& Pierce, 2004), örgütsel destek, örgütsel adalet, (Ökten, 2015), etik olmayan örgütsel davranışlar (Karadal \& Akyazı, 2015), kontrol algısı (Uçar, 2016), işkoliklik (Dirik \& Eryılmaz, 2016), sanal kaytarma, yenilikçi iş davranışları (Derin, 2018), algılanan kontrol (Kalyoncuoğlu, 2018), babacan liderlik (Bekmezci \& Yıldız, 2019), iș tatmini-lider-üye etkileşimi (Ișık \& Uçar, 2019) gibi kavramların incelendiği görülmektedir.

Resmi sahiplenme yasal dayanaklara bağlıyken, psikolojik sahiplenme ise iş görenlerin bireysel anlamda sahip oldukları hislerine dayandığı araştırmalarla gösterilmiştir. Sahiplik duygusu ile ilgili önemli üç nokta bulunmaktadır (Pierce vd., 2003; akt., Yeșil vd., 2015, s. 65; Pierce vd., 2001, s. 298). Bunlardan birincisi, sahipliğin insana ait bir duygu olduğu, ikincisi kişilerin etrafındaki somut ve soyut tüm objelere karşı oluşan bir duygu olduğu, üçüncüsü ise sahiplik duygusunun kayda değer davranışsal, psikolojik ve duygusal anlamda sonuçlarının bulunduğudur (Pierce vd., 2003; akt., Yeşil vd., 2015, s. 65). Bu açıdan psikolojik sahiplenmeyi insan psikolojisi için olumlu bir fenomen olarak ifade etmek mümkündür.

\subsection{Devamsızlık}

İşletmelerin en önemli üretim faktörlerinden biri olan iş gücünün verimli kullanılması işletmenin amaçlarına ulaşmasında önemli bir rol oynamaktadır. İșletme yönetimi, performans arttırıcı politikalar oluşturarak iş gücünü etkin kullanmak durumundadır. $\mathrm{Bu}$ açıdan işe devamsızlık konusu da önem verilmesi gereken kavramlardan biridir. İșe devamsızlık; çalışanların herhangi bir gerekçesi olmadan veya yöneticisine haber vermeden iște bulunmamasıdır (Tütüncü \& Demir, 2003, s. 152). Başka bir ifadeyle işe devamsızlık; çalışanların çalışma takvimine göre çalışması gerektiği halde iş yerinde bulunmamasıdır (Eren, 2007, s. 267).

Çalışanın mazeretinin olması sebebiyle ișe gelmemesinin devamsızlık sayılıp sayılmayacağı konusunda birbirinden farklı yaklaşımlar bulunmaktadır. Bu yaklaşımlara rağmen devamsızlığın, işçinin herhangi bir sebepten dolayı çalışması gereken süre içerisinde işe gelmemesi noktasında birleșen genel bir kanı vardır (Örücü \& Kaplan, 2001, s. 95). 
İşe devamsızlık; gönüllü ve gönülsüz devamsızlık olarak da ele alınabilmektedir (Shultz, 1998). İșe devamsızlık ile ilgili yapılan çalışmalarda iki çeşit yaklaşım mevcuttur (Jex \& Britt, 2002, s. 155; Nielsen \& Ann, 2008, s. 1331; Ramsey vd., 2008, s. 98). Gönüllü (mazeretsiz) ișe gelmeme (voluntary absenteeism) ve gönülsüz (mazeretli) ișe gelmeme (unvoluntary absenteeism)'dir. Başka bir ortamda bulunmayı tercih edip ișe gitmeme gönüllü devamsızlık olarak ifade edilebilir. İșe devamsızlığın nedeni ne olursa olsun, zaman ve tekrar unsuruna bağlı olarak sosyal ortamla da ilgili olduğu belirtilmektedir. Sosyal unsurun etkilerinden dolayı ișe devamsızlık gönüllü olarak da yapılabilmektedir (Hanebuth, 2005; akt., Bacak \& Yiğit, 2010). Yöneticilerin farkında olmadığı bir durumda, çalışanın çeşitli (psikolojik ya da fiziksel rahatsızlıklar, yakınların rahatsızlığı, özel nedenler, isteksizlik, randevular vb.) sebeplerle tüm gün ya da belirli bir zaman diliminde işe devamsızlık iş kaybına yol açmaktadır (Gregory, 2009; akt., Bacak \& Yiğit, 2010). Çalışanın zorunlu hallerden dolayı ișe gelmemesi ise gönülsüz devamsızlık durumu olarak ifade edilebilir.

Çalışanların devamsızlıkları için gösterdikleri gerekçelerin kabul edilip edilmeyeceği konusu iş yerine göre farklılık göstermektedir. İş yeri tarafından kabul edilen mazeretler ya da olaylar karşısında (sağlık sorunları veya diğer gerekçeler gibi) çalışanın mazeretli işe gelmemesi ile de devamsızlık oluşabilmektedir. Mazereti nedeniyle devamsızlık yapan çalışanın mazeretinin iş yeri tarafından kontrol edilmesi söz konusu değildir. Özellikle sağlık sorunları veya diğer mazeretlerin ne zaman gerçekleșeceği belli değildir. Bu durumda yöneticilerin yapabileceği pek bir şey bulunmamaktadır. Mazeretsiz işe gelmeme de ise durum biraz daha farklıdır. Çalışanların genellikle kişisel amaçları doğrultusunda vereceği karar ile ilgili kontrol bütünüyle kendisindedir (Ramsey vd., 2008, s. 98).

Bazı araştırmalarda, gönüllü ve gönülsüz devamsızlığı ortaya koyan faktörlerin iş yerinin kendine ait özelliklerine bağlı olduğu, kesin bir ayrıma gidilmesine şüphe ile bakılması gerektiği belirtilmektedir. Yalnızca mazeretsiz işe gelmeme konusunun çalışan motivasyonu ve iş memnuniyeti gibi psikolojik faktörlerle ilgili olduğu açıklanmaktadır (Kristensen vd., 2006, s. 1645). İster gönüllü ister gönülsüz devamsızlık olsun, devamsızlığın nedenleri şu şekilde sıralanabilir: Hastalık, yakınlarından birinin ölümü, yakınlarla ilgili yaşanan acil durumlar, çalışanların fiziksel rahatsızlıkları, uykunun alınamaması, fazla alkol kullanımı, sabah ișe gitmeme isteğinin yanı sıra (Bacak \& Yiğit, 2010), iş yerinden kaynaklı; iş memnuniyetinde azalma, olumsuz çalışma koşulları, yöneticilerin çalışanlara karşı adil olmayan tutum ve davranışları, işlerin rutin ve sıkıcı olması gibi nedenler bulunmaktadır (Levine, 2009, akt., Bacak \& Yiğit, 2010).

Devamsızlıkla ilgili yapılmış olan araştırmalara göre; çalışma süresi ile iş tatmini arasında olumlu yönde ilişki bulunurken, devamsızlık ile arasında olumsuz ilişki bulunmaktadır. Kișisel demografik değișkenlerin devamsızlığı etkilediği yapılan çalışmalarla ortaya konulmuştur. Çalışanların aile ve çocuk sahibi olmasının işe devamsızlık davranışları üzerinde etkili olabileceği gösterilmiştir (Burton, Holtom \& Lee 2002; akt., Şenel, 2012). Medeni durum ve sahip olunan çocuk sayısının devamsızlığı azalttığı söylenebilir (Golberg ve Waldman, 2000, s 665). Bekâr çalışanın, evli ve çocuk sahibi çalışana kıyasla daha fazla devamsızlık yaptığı ifade edilmektedir (Eren, 2007, s. 268; Bacak \& Yiğit, 2010, s. 32). Yaş (Clegg, 1983; Steel vd., 1990, s. 423), eğitim seviyesi (Clegg, 1983, s. 88; Steel vd., 1990, s. 423), cinsiyet (Hammer vd., 1981, s. 561; Steel vd., 1990, s.423) ile devamsızlık üzerine birçok araștırma yapılmıştır. Çalışanların eğitim seviyesi, hizmet süresi, kıdem gibi unsurların da örgütsel devamsızlık davranışı üzerinde etkisi olduğu belirlenmiştir (Harrison \& Martocchio, 1998, s. 305). Çalışanın yaşı ilerledikçe iş ortamından kaynaklı gerginlik ve sağlığının bozulması gibi nedenlerle devamsızlı̆̆ın arttığı bulunmuştur (Örücü \& Kaplan, 2001, s. 97; Nielsen \& Ann, 2008, s. 1333; Bacak \& Yiğit, 2010, s. 32). Cinsiyetin devamsızlık üzerinde etkisinin araştırıldığı 
çalışmada kadınların devamsızlığa daha fazla eğilimli oldukları belirlenmiştir (Herting, 1993; akt., Şenel 2012). Devamsızlığı etkileyen faktörlerin incelendiği çalışmada, kadın çalışanların erkek çalışanlardan daha sık ama daha az sürelerde devamsızlık yaptıkları sonucuna varılmıștır (Farrel \& Stamm, 1988, akt., Şenel, 2012). Bazı araștırmalarda erkek çalışanların yaşlandıkça devamsızlığının azaldığı, kadın çalışanlar için ise aynı durumun geçerli olmadığı görülmüştür (Ramsey vd., 2008, s. 99). Çalışanların hizmet yıllarının ve yaşlarının devamsızlık ile arasında olumlu yönde ilişki olduğu belirlenmiştir (Harrison \& Martocchio, 1998, s. 316). Çalıșanların gönüllü ya da gönülsüz ișe devamlarının azaltılması için psikolojik sahiplenmenin oluşturulmasına yönelik politikalar uygulanabilir.

Tüm bu kavramlar incelendiğinde iş gücü kaybına neden olan devamsızlığın negatif örgütsel davranış eğilimine neden olduğu belirtilebilir. Tam tersi olan çalışanın çalıştığı iş yerini kendi mülki gibi görmesi olarak tanımlanan psikolojik sahiplenmenin ise pozitif örgütsel davranış eğilimine neden olacağı söylenebilir. Psikolojik sahiplenmenin devamsızlı̆̆ı etkileyeceği ve aralarında ters yönlü bir ilişsi olacağı düşünülmektedir. Bu iki kavramın birlikte ele alındığı araștırmalara pek rastlanılmamıș olması, araștırma bulgularının işletme yönetimine ve literatüre katkı sağlayacağını göstermektedir.

\section{ARAȘTIRMANIN YÖNTEMİ}

\subsection{Araştırmanın Amacı, Kapsamı ve Yöntemi}

Araştırmanın amacını; havacılık sektöründe çalışanların psikolojik sahiplenme algılarının işe devamsızlığı etkileyip etkilemediğinin ölçülmesi oluşturmaktadır. Bu ilișkinin belirlenmesi amacıyla nicel bir araștırma planlanmıștır. Literatür araștırması sırasında bu iki kavram ile birlikte havacılık sektöründe pek fazla araştırma olmadığı görülmüştür. $\mathrm{Bu}$ araștırma ile literatüre ve araştırma yapanlara katkı sağlayacağı düşünülmektedir.

\subsection{Araştırmanın Evreni, Örneklemi ve Ölçekleri}

Araştırmanın amacı doğrultusunda; İstanbul Sabiha Gökçen ve Kocaeli Cengiz Topel' de bulunan hava alanında etkinlik gösteren özel havayolu şirketleri araștırma evrenini oluşturmaktadır. Örneklem olarak iki farklı havayolu şirketi seçilmiștir. Her iki şirketin belirtilen hava alanlarında çalışan sayısı toplam 270 kişidir. Kolayda örneklem metodunun kullanıldığı araştırmaya gönüllü olarak katılımı sağlanan 178 çalışan katılmıştır. Araştırma betimleyici bir özellik göstermektedir. Araştırma sürecinde nicel yöntem benimsenmiș, veriler anket çalışması yapılarak toplanmıștır. Anket çalıșmasında devamsızlık ölçeği ile psikolojik sahiplenme ölçeği kullanılmıştır. Araştırma verileri 2019 yılı içerisinde toplanmıştır.

\section{3. Ölçeklerin Geçerlik ve Güvenirlik Analizleri}

Devamsızlık ölçeği: Nicholson ve Payne (1987) tarafından geliştirilen ölçek iki boyuttan oluşmaktadır. Paget ve arkadaşlarının (1998) kullandıkları ölçeğin gönüllü devamsızlık boyutunun güvenirliği 0,87 ; gönülsüz devamsızlık boyutunun güvenirliği 0,67'dir.

Psikolojik sahiplenme ölçeği: Uçar (2018) tarafından geliştirilen ölçeğin güvenirliği 0,922 olarak hesaplanmıştır. Ölçekler 5'li likert tipinde hazırlanmıștır. 


\section{BULGULAR}

Araştırmanın verileri IBM SPSS 21 programı ile analiz edilmiştir. Verilerin analizinde anlamlılık değeri 0,05 olarak kabul edilmiştir. Normal dağılımın görüldüğü verilerde korelasyon analizi ve regresyon analizi uygulanmıștır. Analiz sonucunda elde edilen bulgular așağıda gösterilmiștir:

Devamsızlık ölçeğine uygulanan faktör analizine göre; KMO $(0,813)$ ve anlamlılık değerinin $(p=0,00)$; psikolojik sahiplenme ölçeğinin KMO $(0,827)$ ve anlamlılık $(p=0,00)$ olduğu görülmektedir ve bu değerler örneklem büyüklüğünün yeterli olduğunu göstermektedir. Bartlett normal dağılım test sonucuna göre $x^{2}$ değeri 1354,335; serbestlik derecesi 78' dir. Devamsızlık ölçeği iki boyuta dağılmış, birinci boyutun en yüksek faktör yük değeri ,844; en düşük faktör yük değeri ,371; ikinci boyutun en yüksek faktör yük değeri ,917; en düşük faktör yük değerinin ise ,519 olduğu görülmüștür. Devamsızlık ölçeğinin açıkladığı toplam varyans değeri 59,785' tir. Psikolojik sahiplenme ölçeğinin açıkladığı varyans oranı ise 61,446 'dır.

Tablo 1: Güvenirlik Katsayıları

\begin{tabular}{|c|c|c|c|}
\hline Faktör & $\begin{array}{c}\text { Cronbach } \\
\text { Alfa }\end{array}$ & Faktör & $\begin{array}{c}\text { Cronbach } \\
\text { Alfa }\end{array}$ \\
\hline Devamsızlık & 0,811 & $\begin{array}{c}\text { Psikolojik } \\
\text { sahiplenme }\end{array}$ & 0,812 \\
\hline Gönüllü devamsızlık & 0,831 & Kimlikleştirme & 0,871 \\
\hline Gönülsüz devamsızlık & 0,864 & Koruyucu odak & 0,809 \\
\hline & & İçsel sorumluluk & 0,760 \\
\hline
\end{tabular}

Devamsızlık ve psikolojik sahiplenme ölçeğinin güvenirlik değerleri Tablo 1' de gösterilmiştir. Buna göre devamsızlık ve psikolojik sahiplenme ölçeğinin güvenirlik değerlerinin yüksek olduğunu belirtmek mümkündür.

Tablo 2: Ölçek ve Boyutlarının Korelasyon Değerleri

\begin{tabular}{|l|c|c|c|l|c|c|c|}
\hline Değişkenler & D & GL & GS & PS & K & KO & IS \\
\hline Devamsızlık (D) & 1 &, $706^{*}$ &, $819^{* *}$ &,- 038 &, $240^{* *}$ &,$- 457^{* *}$ &,$- 177^{*}$ \\
\hline $\begin{array}{l}\text { Gönüllü devamsızlık } \\
\text { (GL) }\end{array}$ & & 1 &, $173^{*}$ &,$- 180^{*}$ &, 105 &,$- 493^{* *}$ &,$- 340^{* *}$ \\
\hline $\begin{array}{l}\text { Gönülsüz devamsızlık } \\
\text { (GS) }\end{array}$ & & 1 &, 094 &, $249^{* *}$ &,$- 237^{* *}$ &, 029 \\
\hline $\begin{array}{l}\text { Psikolojik sahiplenme } \\
\text { (PS) }\end{array}$ & & & 1 &, $869^{* *}$ &, $695^{* *}$ &, $549^{* *}$ \\
\hline Kimlikleştirme(K) & & & & & 1 &, $284^{* *}$ &, $201^{* *}$ \\
\hline $\begin{array}{l}\text { Koruyucu odaklılık } \\
\text { (Ko) }\end{array}$ & & & & & 1 &, $542^{* *}$ \\
\hline İçsel sorumluluk (IS) & & & & & & & 1 \\
\hline
\end{tabular}

${ }^{* *} \mathrm{p}<0,01 ;{ }^{*} \mathrm{p}<0,05$

Korelasyon katsayısı -1 ile +1 arasında bir değer alır; 0.00-0.49 arası zayıf bir ilişkiyi, $0.50-0.69$ arası orta düzey bir ilișkiyi, 0.70-1.0 arası yüksek düzey bir ilișkiyi işaret eder. Psikolojik sahiplenme ile devamsızlık arasında anlamlı bir ilişki bulunamamıștır. Ancak devamsızlık ile kimlikleştirme (r:0,240) arasında zayıf ve doğru yönlü; kontrol odaklılıkla (r:-0,457) ters ve orta düzeyde, içsel sorumlulukla (r:-0,177) 
ters ve zayıf bir ilişki bulunmaktadır. Gönüllü devamsızlık ile psikolojik sahiplenme (p:0,180 ) arasında zayıf ve ters yönlü; kontrol odaklılık (r:-0,493), içsel sorumlulukla (r:0,340 ) zayıf ve ters yönlü bir ilişki bulunmaktadır. Gönülsüz devamsızlıkla kimlikleștirme boyutu (r:0,249) arasında doğru ve zayıf bir ilișki, kontrol odaklılık (r:-0,237) arasında ters ve zayıf bir ilişki görülmüştür.

Tablo 3: Psikolojik Sahiplenme ve Alt Boyutlarının Devamsızlıkla İlişkisi

\begin{tabular}{|l|l|l|l|l|l|l|l|}
\hline Bağımsız değişken & $\mathbf{R}$ & $\mathbf{R}^{\mathbf{2}}$ & $\mathbf{B}$ & $\boldsymbol{\beta}$ & $\mathbf{T}$ & $\mathbf{F}$ & $\mathbf{P}$ \\
\hline Psikolojik sahiplenme &, 038 &, 001 &,- 036 &,- 038 & $-0,500$ &, 250 &, 618 \\
\hline Kimlikleştirme &, 240 &, 057 &, 319 &, 240 & 3,275 & 10,722 &, 01 \\
\hline Koruyucu Odaklılık &, 457 &, 209 & $-1,142$ &,- 457 & $-6,820$ & 46,518 &, 00 \\
\hline İçsel sorumluluk &, 177 &, 031 &,- 861 &,- 177 & $-2,387$ & 5,699 &, 018 \\
\hline Psikolojik sahiplenme &, 180 &, 033 &,- 101 &,- 180 & $-2,433$ & 5,920 &, 016 \\
\hline Kimlikleștirme &, 105 &, 011 &, 081 &, 105 & 1,399 & 1,957 &, 164 \\
\hline Koruyucu Odaklılık &, 493 &, 243 &,- 717 &,- 493 & $-7,515$ & 46,518 &, 00 \\
\hline İçsel sorumluluk &, 340 &, 115 &,- 961 &,- 340 & $-4,792$ & 56,480 &, 00 \\
\hline Psikolojik sahiplenme &, 094 &, 009 &,- 101 &, 094 & 1,249 & 1,560 &, 213 \\
\hline Kimlikleștirme &, 249 &, 062 &, 238 &, 249 & 3,404 & 11,587 &, 001 \\
\hline Koruyucu Odaklılık &, 237 &, 056 &,- 425 &,- 237 & $-3,237$ & 10,477 &, 001 \\
\hline İçsel sorumluluk &, 029 &, 001 &, 100 &, 029 & 0,381 &, 145 &, 704 \\
\hline
\end{tabular}

Bağımlı değișken "Devamsızlık”, “Gönüllü Devamsızlık”, “Gönülsüz Devamsızlık” $p<0,05$

Regresyon analizine göre; anlamlılık düzeyi 0,618>0,05 olduğundan psikolojik sahiplenme ile devamsızlık arasında bir ilişki bulunmamaktadır. Regresyon analizine göre; anlamlılık düzeyi $0,01<0,05$ olduğundan kimlikleştirme ile devamsızlık arasında bir ilișki bulunmaktadır. Kimlikleștirme boyutunda meydana gelen "1" birimlik artış, devamsızlık üzerinde 0,240 oranında artışa neden olur. Regresyon analizine göre; anlamlılık düzeyi $0,00<0,05$ olduğundan koruyucu odaklılık ile devamsızlık arasında bir ilişki bulunmaktadır. Koruyucu odaklılık boyutunda meydana gelen "1" birimlik artış, devamsızlık üzerinde 0,457 oranında azalışa neden olur. Regresyon analizine göre; anlamlılık düzeyi $0,018<0,05$ olduğundan içsel sorumluluk ile devamsızlık arasında bir ilişki bulunmaktadır. İçsel sorumluluk boyutunda meydana gelen "1" birimlik artış, devamsızlık üzerinde 0,177 oranında azalışa neden olur.

Regresyon analizine göre; anlamlılık düzeyi 0,016<0,05 olduğundan psikolojik sahiplenme ile gönüllü devamsızlık arasında bir ilişki bulunmaktadır. Psikolojik sahiplenme boyutunda meydana gelen "1" birimlik artıș, gönüllü devamsızlık üzerinde 0,180 oranında azalışa neden olur. Regresyon analizine göre; anlamlılık düzeyi 0,164>0,05 olduğundan kimlikleştirme ile gönüllü devamsızlık arasında bir ilişki bulunmamaktadır. Regresyon analizine göre; anlamlılık düzeyi $0,00<0,05$ olduğundan koruyucu odaklılık ile gönüllü devamsızlık arasında bir ilișki bulunmaktadır. Koruyucu odaklılık boyutunda meydana gelen "1" birimlik artış, devamsızlık üzerinde 0,493 oranında azalışa neden olur. Regresyon analizine göre; anlamlılık düzeyi $0,00<0,05$ olduğundan içsel sorumluluk ile gönüllü devamsızlık arasında bir ilişki bulunmaktadır. İçsel sorumluluk boyutunda meydana gelen "1" birimlik artış, gönüllü devamsızlık üzerinde 0,340 oranında azalışa neden olur.

Regresyon analizi sonuçları incelendiğinde; anlamlılık düzeyi 0,213>0,05 olduğundan psikolojik sahiplenme ile gönülsüz devamsızlık arasında bir ilişki bulunmamaktadır. Regresyon analizine göre; anlamlılık düzeyi $0,001<0,05$ olduğundan kimlikleştirme ile gönülsüz devamsızlık arasında bir ilişki bulunmaktadır. Kimlikleştirme boyutunda meydana gelen "1" birimlik artış, gönülsüz devamsızlık üzerinde 0,249 
oranında artışa neden olur. Regresyon analizine göre; anlamlılık düzeyi $0,001<0,05$ olduğundan koruyucu odaklılık ile gönülsüz devamsızlık arasında bir ilişki bulunmaktadır. Koruyucu odaklılık boyutunda meydana gelen "1" birimlik artış, gönülsüz devamsızlık üzerinde 0,237 oranında azalıșa neden olur. Regresyon analizine göre; anlamlılık düzeyi $0,704>0,05$ olduğundan içsel sorumluluk ile gönülsüz devamsızlık arasında bir ilişki bulunmamaktadır. Devamsızlık ve psikolojik sahiplenme ölçeğinin güvenirlik değerleri Tablo 1' de gösterilmiştir. Buna göre devamsızlık ve psikolojik sahiplenme ölçeğinin güvenirlik değerlerinin yüksek olduğunu belirtmek mümkündür.

\section{Değerlendirme ve Sonuç}

Psikolojik sahiplenmedeki içsel sorumluluk duygusunun; kişinin işini sorumluluk olarak görmesine neden olduğu söylenebilir. Hasta olunduğunda ya da ailevi sorunlar yaşandığında ve hatta cenaze gibi olumsuz durumlarda bile yüksek içsel sorumluluk duygusu bireyi ișe gitmekten yana tavır almaya itmektedir.

Kimlikleştirme kültürel açıdan incelendiğinde sanki kendine aitmiş düşüncesiyle devamsızlıkla ve gönülsüz devamsızlıkla doğru yönlü ilișki halindedir. Kimlikleștirme artıkça gönülsüz devamsızlık da artmaktadır. Psikolojik sahiplenmede kişinin çalışılan kurumu bir kimlik gibi görmesi devamsızlıkta ve devamsızlığın alt boyutlarında bir artışa neden olmaktadır.

Koruyucu odaklılık artıkça devamsızlık ve gönülsüz devamsızlık azalır. Benzer bir durum da içsel sorumlulukla devamsızlık arasında mevcuttur. Sorumluluk benimsendikçe devamsızlıkta azalma meydana gelmektedir.

Psikolojik sahiplenme arttıkça gönüllü devamsızlıkta azalma meydana gelmektedir. Koruyucu odaklılık artıkça gönüllü devamsızlık azalmaktadır. İçsel sorumluluk artıkça gönüllü devamsızlık azalır. Düşük iş tatmini örgüt personelinin işten ayrılma niyetini ve işe devamsızlığını artırmaktadır (Bacak \& Yiğit, 2010). Çalışma yaşamının kalitesinin yüksek olması işe devamsızlık oranını düşürmektedir (Demir, 2011). Jex (2002) işe devamsızlığın öncüllerinden birinin psikolojik unsurlar olduğunu belirtmektedir. Bu sonuç; olumlu psikolojik duyguların devamsızlık üzerinde pozitif yönlü bir etkisi olduğunu desteklemektedir.

Derin (2018) yapmış olduğu araştırmada psikolojik sahiplenme ile olumlu davranış olarak nitelendirilebilen yenilikçi iş davranışları arasında pozitif yönlü bir ilişki bulurken olumsuz bir davranış olarak değerlendirilen sanal kaytarmanın düzenleyici bir rol üstlendiğini belirlemiştir.

Araştırmanın bir takım kısıtları bulunmaktadır. Araştırma maddiyat ve zaman sınırı düşünülerek Sabiha Gökçen ve Cengiz Topel havaalanlarında faaliyet gösteren iki havayolu işletmesinde gerçekleștirilmiştir. Araştırmaya katılımın gönüllülük esasına dayalı olması ve katılımcıların anket formunu dürüstçe cevapladığının varsayılması da diğer bir kısıttır.

Devamsızlık geçici iş gücü kaybı, işletmeye ekstra bir maliyet getirmektedir. Çalışanların ișe devam etmesini sağlamak amacıyla psikolojik sahiplenmeye yönelik insan kaynakları politikalarının oluşturulması önemlidir. Yine benzer bir sonuç olarak işe alım aşamasında işe alınacak adaylara uygulanan kişisel ve psikolojik testler psikolojik sahiplenmeyi ölçebilecek ş̧ekilde düzenlenebilir. Havacılık sektöründe psikolojik sahiplenme ile devamsızlık arasında doğrudan bir ilişki tespit edilememiş olsa bile devamsızlığın alt boyutlarıyla psikolojik sahiplenme arasında bir ilişkinin olduğu görülmektedir. Havacılık sektörünün günümüzde prestijli bir yere sahip olduğu ve mevcut sektörde faaliyet gösteren işletmelerin az sayıda olduğu da bir gerçektir. Bu açıdan mevcut sektördeki çalışanların çalıştıkları örgütü sahiplenmeleri ve devamsızlık oranlarını düşürmeleri insan kaynakları yönetimi açısından hoşnut bir durumdur. Mevcut 
çalışmanın farklı sektörlerde uygulanmasının elde edilen bulguları zenginleștireceği düşünülmektedir.

\section{KAYNAKÇA}

AVEY, J. B., AVOLIO, B. J., CROSSLEY, C. D., ve LUTHANS, F. (2009). Psychological ownership: theoretical extensions, measurement and relation to work outcomes, Journal Of Organizational Behavior, 30(2), 173-191.

BACAK, B. ve YİĞİT, Y. (2010). İșe devamsızlığın nedenleri, ekonomik sonuçları ve azaltılması için alınması gereken önlemler. Girişimcilik ve Kalkınma Dergisi, 5(1), 2944.

BROWN, G., LAWRENCE, T. B. ve ROBİNSON, S. L. (2005). Territoriality in organizations. Academy of Management Review, 30(3), 577-594.

CLEGG, C. (1983). Psychology of employee latenes, absence and turnover: a methodological critique and an empirical study. Journal of Applied Psychology, 68(1), 88101.

EREN, E. (2007). Örgütsel davranış ve yönetim psikolojisi. Beta Yayınları, İstanbul.

DEMIR, M. (2011). İşgörenlerin çalışma yaşamı kalitesi algılamalarının işte kalma niyeti ve ișe devamsızlı ile ilișkisi. Ege Akademik Bakış, 11(3), 453-464.

DERİN, N. (2018). Kuruma duyulan psikolojik sahiplenme ile yenilikçi iş davranışı arasındaki ilişkide sanal kaytarmanın düzenleyici rolü. Hacettepe Üniversitesi Íktisadi ve Ídari Bilimler Fakültesi Dergisi, 36 (1) , 63-81.

GOLDBERG, C. ve WALDMAN, D. (2000). Modeling employee absenteeism: testing alternative measures and mediated effects based on job satisfaction. Journal of Organizational Behavior, 21, 665-676.

HAMMER, T., LANDAU, J., ve STERN, R. (1981). Absenteeism when workers have a voice: the case of employee ownership. Journal of Applied Psychology, 66(5), 561-573.

HARRISON, D. ve MARTOCCHIO, J. (1998). Time for absenteeism: a 20-year review of origins, offshoots, and outcomes. Journal of Management, 24(3), 305-350.

https://www.apronmedya.com/turkiyede-havacilik-sektorunde-ne-kadar-kisicalisiyor/. (erişim tarihi: 13.08.2020).

https://www.ekonomihaber.com/is-yasam/turkiye-sivil-havacilik-cirosu-110milyar-liraya-ulasti-h30928.html (2019). (erişim tarihi: 13.08.2020).

https://www.uab.gov.tr/uploads/pages/havacilik/havacilik.pdf, (2018). Ulaşan ve erișen Türkiye havacılık ve uzay teknolojileri, 356-448. (erişim tarihi: 13.08.2020).

ISSIK, M. \& UÇAR, Z. (2019). İș tatmini psikolojik sahiplenme ilişkisinde lider üye etkileșiminin düzenleyicilik etkisi. Dokuz Eylül Üniversitesi Sosyal Bilimler Enstitüsü Dergisi, 21(4), 1119-1145.

JEX, S. ve BRITT, T. (2002). Organizational psychology: a scientist-ractitioner approach. John Wiley \& Sons, New York.

JEX, S. M. (2002). Organizational psychology: a scientist-practitioner approach. John Wiley \& Sons, New York.

KRISTENSEN, K., JUHL, H. J., ESKILDSEN, J., NIELSEN, J., FREDERIKSEN, N. ve BISGAARD, C. (2006). Determinants of absenteeism in a large Danish bank. International Journal of Human Resource Management, 17(9), 1645-1658.

LERNER, J. S. ve TETLOCK, P. E. (1999). Accounting for the effects of accountability. Psychological Bulletin, 125, 255-275.

LITWINSKI, L. (1947). The psychology of mine. Philosophy, 22(83), 240-251. 
MAYHEW, M., ASHKANASY, N., BRAMBLE, T. ve GARDNER, J. (2007). A study of the antecedents and consequences of psychological ownership in organizational settings. The Journal of Social Psychology, 147(5), 477-500.

NIELSEN, L. ve ANN, K. (2008). Determinants of absenteeismin public organizations: a unit-level analysis of work absence in a large danish municipality. The International Journal of Human Resource Management, 19(7), 1330-1348.

ÖRÜCÜ, E. ve KAPLAN, E. (2001). Kamu ve özel sektör çalışanlarında devamsızlık sorunu. Celal Bayar Üniversitesi I.I.I.B.F. Yönetim ve Ekonomi Dergisi, 7(1), 93-112.

PAGET, K., LANG, D. ve SHULTZ, K. (1998). Development and validation of an employee absenteeism scale, Psychological Reports, 82, 1144-1146.

PIERCE, J. ve JUSSILA, I. (2010). Collective psychological ownership within the work and organizational context: construct introduction and elaboration. Journal of Organizational Behavior, 31, 810-834

PIERCE, J., KOSTOVA, T. ve DIRKS, K. (2001). Toward a theory of psychological ownership in organizations. Academy of Management, 26(2), 298-310.

PIERCE, J. ve RODGERS, L. (2004). The psychology of ownership and workerowner productivity. Group \& Organization Management, 29(5), 588-613.

RAMSEY, J., PUNNETT, B. J. ve GREENIDGE, D. (2008). A social psychological account of absenteeism in Barbados. Human Resource Management Journal, 18(2), 97 117.

RUSSELL, W. B. (1988). Possessions and the extended self. Journal of Consumer Research, 15, 139-168.

STEEL, R., SHANE, G. ve KENNEDY, K. (1990). Effects of social-system factors on absenteeism, turnover and job performance. Journal of Business and Psychology, 4(4), 423-430.

SHULTZ, K. (1998). Development and validation of an employee absenteeism scale. https://www.researchgate.net/publication/293647365.

ŞENEL, B. (2012). Devamsızlık nedenleri ve maliyetinin araştırılması. Marmara Sosyal Araştırmalar Dergisi, 3, 1-18.

TÜTÜNCÜ, Ö. ve DEMİR, M. (2003). Konaklama işletmelerinde insan kaynakları kapsamında işgücü devir hızının analizi ve Muğla bölgesi analizi. Dokuz Eylül Üniversitesi Sosyal Bilimler Enstitüsü Dergisi, 5(2), 1-24.

UÇAR, Z. (2017). Psikolojik sahiplenme: örgütsel alana ilişkin bir model önerisi. Dokuz Eylül Üniversitesi İktisadi ve İdari Bilimler Fakültesi Dergisi, 32(1), 167-200.

VAN DYNE, L. ve PIERCE, J. L. (2004). Psychological ownership and feelings of possession: three field studies predicting employee attitudes and organizational citizenship behavior. Journal of Organizational Behavior, 25(4), 439-459.

YEŞiL, Ü., BANCAR, A. ve BUDAK, G. (2015). Psikolojik sahiplik kavramına ilișkin bir literatür incelemesi. Eskişehir Osmangazi Üniversitesi Sosyal Bilimler Dergisi, 16(2), 59-82.

\section{Summary}

Under strong competition, organizations face more and more challenges to compete. Changing and developing technology has increased the importance of efficient use of human resources as well as new techniques and methods in production. Human resources are one of the important production factors of organizations. In this context, organizations play an important role in achieving their goals. In this study, it was aimed to determine the relationship between absenteeism and psychological ownership in the health sector. 
Istanbul Sabiha Gokcen and the private airline companies operating in the airport in Kocaeli constitute the research universe. Two different airline companies were selected as a sample. The total number of employees working in the specified airports is 270 people. A total of 178 volunteers were included in the study. In the research process, quantitative method was adopted and data were collected by survey. In the questionnaire, absenteeism scale and psychological ownership scale were used.

The data of the study were analyzed with IBM SPSS 21 program. In the analysis of the data, the significance value was accepted as 0.05. Correlation analysis and regression analysis were applied to the data with normal distribution. No significant correlation was found between psychological ownership and absenteeism. However, the weakness and the right direction between absenteeism and identity; There is an inverse and weak relationship with internal and external responsibility. Voluntary absenteeism and psychological ownership are weak and inverse; There is a weak and inverse relationship with control and internal responsibility. An inverse and weak relationship was observed between the reluctance of absenteeism and the identity dimension with a correct and weak relationship, and control orientation. According to the regression analysis; Since the level of significance is $0,016<0,05$, there is a relationship between psychological ownership and voluntary absenteeism. "1" unit increase in the level of psychological ownership causes a decrease of 0.180 on voluntary absenteeism. According to the regression analysis; since the level of significance is $0.164>0.05$, there is no relationship between identity and voluntary absenteeism. According to the regression analysis; Since the significance level is $0.00<0.05$, there is a relationship between protective focus and voluntary absenteeism. The " 1 " unit increase in the protective orientation dimension causes a decrease of 0.493 on absenteeism. According to the regression analysis; Since the significance level is $0.00<0.05$, there is a relationship between internal responsibility and voluntary absenteeism. The " 1 " unit increase in the dimension of internal responsibility leads to a decrease of 0.340 on voluntary absenteeism.

According to the regression analysis; Since the level of significance is $0.213>0.05$, there is no relationship between psychological ownership and involuntary absenteeism. According to the regression analysis; Since the significance level is $0.001<0.05$, there is a relationship between identity and involuntary absenteeism. The 1-unit increase in the identity dimension results in an increase of 0.249 on the involuntary absenteeism. According to the regression analysis; Since the significance level is $0.001<0.05$, there is a relationship between protective focus and involuntary absenteeism. The üzerinde 1 unit increase in the protective orientation dimension causes a decrease of 0.237 on the reluctant absenteeism. According to the regression analysis; Since the level of significance is 0.704>0.05, there is no relationship between internal responsibility and involuntary absenteeism. When identity is examined from a cultural point of view, employees feel like the owner of the organization. It has a correct relationship with voluntary and involuntary absenteeism. As the degree of identity increases, involuntary absenteeism increases. In psychological ownership, the employee's view of his organization as an identity causes an increase in the subdimensions of absenteeism and absenteeism. As the protective focus increases, absenteeism and involuntary absenteeism decrease. A similar situation exists between internal responsibility and absenteeism. The decrease in absenteeism occurs as the responsibility is adopted. As psychological ownership increases, there is a decrease in voluntary absenteeism. Voluntary absenteeism decreases as protective focus increases. Voluntary absenteeism decreases as internal responsibility increases.

The loss of temporary work force brings an extra cost to the enterprise. It is important to establish human resources policies for psychological ownership in order to ensure that employees continue to work. Similarly, personal and psychological tests applied to candidates to be recruited during the recruitment phase can be designed to measure 
psychological ownership. Even though there is no direct relationship between psychological ownership and absenteeism in aviation sector, it is seen that there is a relationship between the sub-dimensions of absenteeism and psychological ownership. It is a fact that the aviation sector has a prestigious place and the number of enterprises operating in the current sector is few. In this respect, employees in the current sector have the ownership of the organization they work in and the decrease in absenteeism rates is satisfactory in terms of human resources management. It is thought that the application of the present study in different sectors will enrich the findings obtained. 